\title{
Benign Nasopharyngeal Neoplasm
}

National Cancer Institute

\section{Source}

National Cancer Institute. Benign Nasopharyngeal Neoplasm. NCI Thesaurus. Code C3595.

A non-metastasizing neoplasm that arises from the nasopharynx. Nasopharyngeal angiofibroma is a representative example. 